Journal of Engineering and Applied Sciences 14 (Special Issue 8): 10430-10433, 2019

ISSN: $1816-949 \mathrm{X}$

(C) Medwell Journals, 2019

\title{
Gender as a Moderator in the Relationship between Violent Video Games Play and Aggressive Behaviour among In-School Adolescents
}

\author{
${ }^{1}$ Emenike N. Anyaegbunam, ${ }^{2}$ Chiedu Eseadi, ${ }^{3}$ Chinyere Augusta Nwajiuba, ${ }^{2}$ Paul N. Onwuasoanya, \\ ${ }^{3}$ Oluchi Queen Onwudinjo, ${ }^{3}$ Rowland C. Uwakwe, ${ }^{3}$ Ngozi Awoke, ${ }^{1}$ Iheanacho Christian Agboti, \\ ${ }^{2}$ Godfrey Chinweike Nji and ${ }^{2}$ Michael Eskay \\ ${ }^{1}$ Faculty of Management and Social Sciences, Alex Ekwueme Federal University Ndufu-Alike Ikwo, \\ Ebonyi State, Nigeria \\ ${ }^{2}$ Faculty of Education, University of Nigeria Nsukka, PMB 410001, Enugu State, Nigeria. \\ ${ }^{3}$ Faculty of Education, Alex Ekwueme Federal University Ndufu-Alike Ikwo, Ebonyi State, Nigeria
}

\begin{abstract}
The purpose of this study was to as certain if gender is a moderator in the relationship between violent video games play and aggressive behaviour among in-school adolescents in Nigeria. The study employed correlational survey design. The study was conducted among in-school adolescents in Onitsha Education Zone of Anambra State, Nigeria. The sample size was 603 in-school adolescents comprising of 348 male and 255 female students in senior secondary class two. The Violent Video Games Questionnaire (VVGQ) and In-School Adolescents' Aggressive Behaviour Questionnaire (IAABQ) were used for data collection. Mean, partial correlation and chart were used to interpret the research questions while linear regression analysis was used to test the hypothesis at 0.05 probability level. Results revealed that the extent to which gender moderates the relationship between violent video games play and aggressive behaviour among in-school adolescents is very high. It was also found that gender is a significant moderator in the relationship between violent video games play and aggressive behaviour among in-school adolescents. Future research could investigate the influence of violent video games on in-school adolescent's academic achievement orientation.
\end{abstract}

$\underline{\text { Key words: Aggressive behaviour, gender, in-school adolescents, violent video games, significant, moderator }}$

\section{INTRODUCTION}

Video games are audio-visual digital games in which players may tend to automatically perceive the virtual characters as social beings that deserve proper moral treatment (Hartmann et al., 2010). Kooijmans (2004) noted that the first generation of video games made their first appearance in 1970s with simple shapes and had minimal interaction. The first video game, Pong, attempted to simulate Ping Pong using two rectangles as paddles and a small square as the ball. The paddles could be controlled by a human player. This video game was quite entertaining and educative to the players. Among the first popular video games to be considered violent according to Kooijmans (2004) was PacMan. The game, according to this researcher, consisted of a small circle with a mouth that tried to eat pills and destroy ghosts. Although, this may hardly be seen as violent act by recent standards, it was one of the first video games considered to have displayed violence.

Violent video games are games with content that enable users to master intentional use of physical force with the potential for causing death, disability, injury or harm (Eseadi, 2016). Kutner et al. (2008) stated that curiosity, control and excitement could attract adolescents to play violent video games. A number of studies suggest that male adolescents play violent video games more frequently than females (Hartmann et al., 2015; Hartmann and Klimmt, 2006; Lemmens et al., 2006; Lucas and Sherry, 2004; Moller and Krahe, 2009). Lucas and Sherry (2004) found that video games play could be mediated by gender norms. A number of studies such as that by Anderson (2004), Anderson and Bushman (2001), Moller and Krahe (2009) and Wallenius and Punamaki (2008) have also documented that violent video games are positively associated with aggressive behaviour and negatively associated with school performance among adolescents.

There are mixed findings concerning whether the gender of adolescents determine how much they are affected by violent video games play. A 2003 study revealed that violent acts in video games could desensitize male adolescents to violence and can make female adolescents more responsive to violence (Deselms and Altman, 2003). However, Moller and Krahe (2009) found that there was no significant difference between male and female adolescents in the amount of aggression experienced as a result of exposure to violent video

Corresponding Author: Godfrey Chinweike Nji, Faculty of Education, University of Nigeria Nsukka, PMB 410001, Enugu State, Nigeria 
games. The aim of the present study was to as certain if gender is a moderator in the relationship between violent video games play and aggressive behaviour among a sample of in-school adolescents in Onitsha Education Zone of Anambra State, Nigeria.

Research question: To what extent does gender moderate the relationship between violent video games play and aggressive behaviour among in-school adolescents?

Hypothesis: Gender will not significantly moderate the relationship between violent video games play and aggressive behaviour among in-school adolescents.

Theoretical review: This study is anchored on the operant conditioning theory. Operant conditioning theory which was developed by Skinner (1938) proposes that people are more likely to repeat behaviours that have been rewarded and are less likely to repeat behaviours that have been punished. Developers of violent video games uses operant conditioning principles to shape game play, since, both negative and positive reinforcements are used to encourage players to quickly and accurately eliminate a threat. Violent video games present a threat to players in the form of enemies that attempt to kill the player's character which serves as an aversive stimulus (Eseadi, 2016). Killing the opponents eliminates the threat and the more quickly and accurately players target the threat, the more quickly the threat is eliminated-a form of negative reinforcement. Positive reinforcement is also given to players for quickly and accurately attacking opponents. Once an opponent is killed, players often earn points and move on to higher levels in the game. In some video games, players are also rewarded through praise after killing an opponent (Eseadi, 2016). These negative and positive reinforcers increase the likelihood that violent actions will be repeated. Therefore, since, violent video games reward players for eliminating threatsin such a manner that align with the operant conditioning theory, the theory is considered relevant to the present study.

\section{MATERIALS AND METHODS}

Study design, area and participants: The study employed correlational survey design. The study was conducted in Onitsha Education Zone of Anambra State, Nigeria. This education zone is made up of two local government areas, namely Onitsha North and Onitsha South. The study population includes all the senior secondary in-school adolescents in government-owned secondary schools in Onitsha Education Zone of Anambra State, Nigeria. The sample for the study comprised 603 (348 males and 255 females) SSS II in-school adolescents selected through a multi-stage sampling procedure. All thein-school adolescents included in this study provided informed assent. Approval to distribute the questionnaires was obtained from the principals of participating schools.

Instruments for data collection: One of the data collection instruments used in this study was Violent Video Games Questionnaire (VVGQ) (Eseadi, 2016) which consist of two sections A and B. Section A contains the respondents' demographic characteristics such as gender. Section B contains a list of 20 violent video games which elicits the extent to which the in-school adolescents play each of the games using a four-point scale ranging from Always (A) to Never (N). Another data collection instrument used in this study was Inschool Adolescents' Aggressive Behaviour Questionnaire (IAABQ) (Eseadi, 2016) which contains 29 item statements regarding aggressive behaviour and respondents have to indicate how much they feel each statement described them on a four-point scale ranging from Always (A) to Never (N). A previous study established the face validity of these questionnaires using three validators and also using Cronbach alpha method, the previous research reported that the VVGQ has a reliability coefficient of 0.82 and the IAABQ has a reliability coefficient of 0.83 (Eseadi, 2016).

Method of data collection and analysis: The questionnaires were distributed to and retrieved on-the-spot from the participating in-school adolescents. In each of the schools, the participants were briefed about the research before asking them to complete the instruments. In addition, one research assistant was used for the purpose of data collection. Mean, partial correlation $\left(\mathrm{r}_{\mathrm{p}}\right)$ and chart were used to answer the research questions while linear regression analysis was used to test the hypothesis at 0.05 probability level. To answer the research question, the following guidelines were applied to ascertain the extent of relationship between the variables using correlation coefficients: 0.80 and above (very high extent); $0.60-0.79$ (high extent), 0.40-0.59 (moderate extent), 0.20-0.39 (low extent) and 0.00-0.19 (very low extent).

\section{RESULTS AND DISCUSSION}

Research question: To what extent does gender moderate the relationship between violent video games play and aggressive behaviour among in-school adolescents?

Results in Table 1 shows that based on gender, the total mean score for playing violent video games was 3.34 with standard deviation of 0.29 for the male in-school adolescents while total mean score of 3.35 with standard deviation of 0.29 was obtained for the female in-school adolescents. Furthermore, the total mean score of the male in-school adolescents on aggressive behaviour was 3.38 


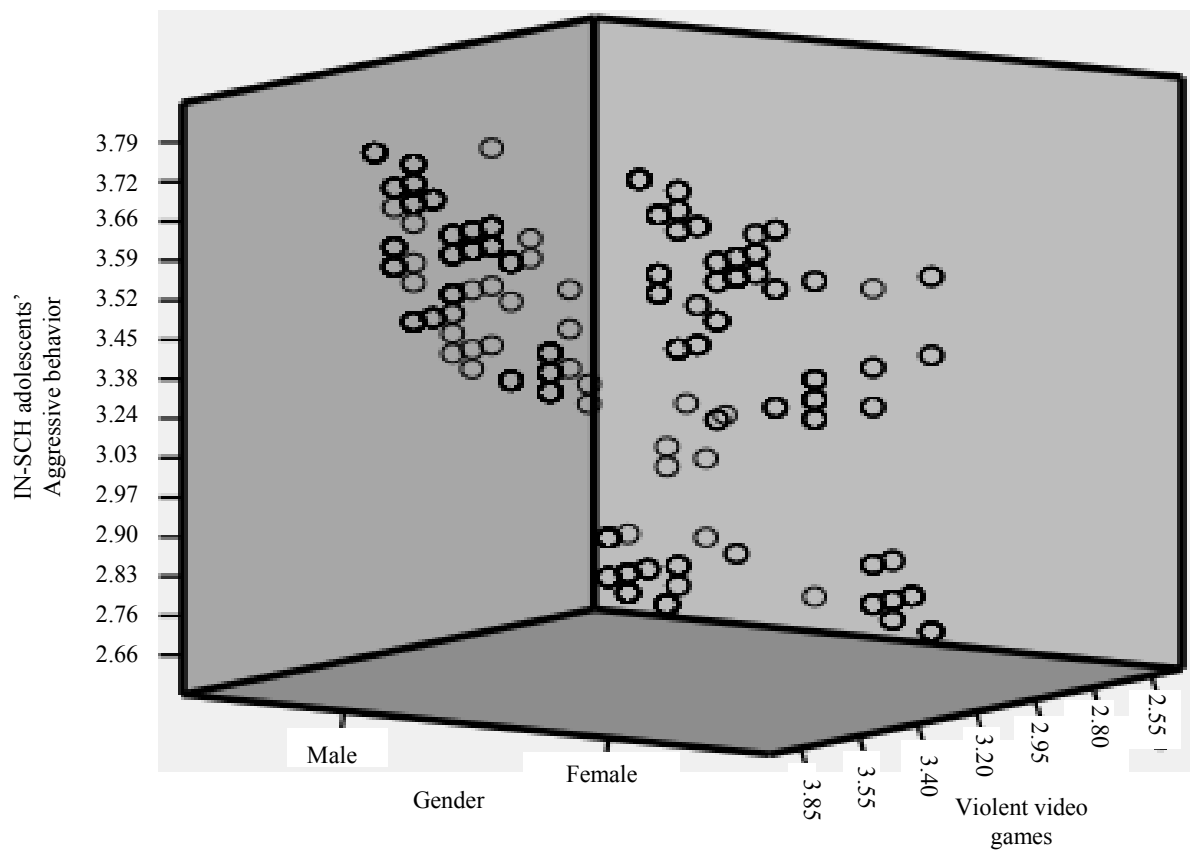

Fig. 1: Chart showing how gender moderates the relationship between violent video games play and aggressive behaviour among in-school adolescents

Table 1: Partial correlation analysisshowing the extent to which gender moderate the relationship between violent video games play and aggressive behaviour among in-school adolescents

\begin{tabular}{llcccl}
\hline Variables & Gender & $\mathrm{N}$ & $\overline{\mathrm{X}} \mathrm{SD}$ & $\mathrm{r}_{\mathrm{n}}$ & Decision \\
\hline Violent video & Male & 348 & $3.34 \pm 0.29$ & 0.86 & Very High Extent \\
games play & Female & 255 & $3.35 \pm 0.29$ & & \\
Aggressive & Male & 348 & $3.38 \pm 0.37$ & & \\
behaviour & Female & 255 & $3.37 \pm 0.36$ & & \\
\hline
\end{tabular}

$\mathrm{N}=$ Number of respondents, $\mathrm{r}_{\mathrm{p}}=$ Partial correlation coefficient

Table 2: Summary of regression analysis showing gender as moderator in the relationship between playing violent video games and aggressive behaviour among in-school adolescents

\begin{tabular}{lcccccc}
\hline Variables & $\mathrm{N}$ & $\mathrm{F}$ & $\mathrm{R}^{2}$ & $\mathrm{~B}$ & Sig. & Decision \\
\hline $\begin{array}{l}\text { Violent video } \\
\text { games play gender }\end{array}$ & 899.56 & 0.75 & 0.866 & 0.000 & Rejected \\
$\begin{array}{l}\text { aggressive behaviour } \\
\mathrm{df}=1.602 ; \mathrm{p}<0.05\end{array}$ & & & & & \\
\hline
\end{tabular}

with standard deviation of 0.37 while the total mean score for the female in-school adolescents on aggressive behaviour was 3.37 with standard deviation of 0.36 . Also, the value of the partial correlation coefficient $\left(r_{p}\right)$ which is 0.86 indicates that the extent to which gender moderates the relationship between violent video games play and aggressive behaviour among in-school adolescents is very high.

Figure 1 is a chart demonstrating how gender moderates the relationship between violent video games play and aggressive behaviour among in-school adolescents. The figure demonstrates that the relationship between violent video games play and aggressive behaviour is being moderated by gender to a very high extent.
Hypothesis: Gender will not significantly moderate the relationship between violent video games play and aggressive behaviour among in-school adolescents.

Results of data analysis in Table 2 show that gender significantly moderate the relationship between violent video games play and aggressive behaviour among in-school adolescents, $R^{2}=0.67, F(1.602)=899.56$, $\beta=0.86, p=0.000$. Since, the exact probability value $(0.000)$ is less than the a priori probability value $(0.05)$, the null hypothesis which states that gender will not significantly moderated the relationship between violent video games play and aggressive behaviour among in-school adolescents is rejected. The $\mathrm{R}^{2}$ value of 0.75 implies that violent video games play accounted for just $75 \%$ of the variance in aggressive behaviour when gender was entered as a moderator variable.

This study found that the extent to which gender moderates the relationship between violent video games play and aggressive behaviour among in-school adolescents is very high. As found, gender significantly moderates the relationship between violent video games play and aggressive behaviour among in-school adolescents. The finding is in agreement with recent study by Eseadi et al. (2019) which showed that gender is a significant moderator in the relationship between violent video games play and aggressive behaviour among adolescent students. Bartholow and Anderson found that game by sex interaction effect was larger for men than for women. On the contrary, Puri and Pugliese 
(2012) found that no significant difference exists between men and women in terms of violent video games and aggressive behaviour. Our findings suggest that gender can influence in-school adolescents' violent video games play and their display of aggressive behaviour. It is recommended that school rules and regulations regarding amount of exposure to violent video contents can be extended to homes and parents should be made to understand that they have vital roles to play regarding in-school adolescents' video games play. Future research could investigate the influence of violent video games on in-school adolescent's academic achievement orientation.

\section{CONCLUSION}

The extent to which gender moderates the relationship between violent video games play and aggressive behaviour among in-school adolescents is very high. Thus, gender is a significant moderator in the relationship between violent video games play and aggressive behaviour among in-school adolescents. Future research could investigate the influence of violent video games on in-school adolescent's academic achievement orientation.

Note: This study was drafted from a completed postgraduate research. Other aspects of the study are under consideration for publication. We are very grateful to all the in-school adolescents who participated in this study.

\section{REFERENCES}

Anderson, C.A. and B.J. Bushman, 2001. Effects of violent video games on aggressive behavior, aggressive cognition, aggressive affect, physiological arousal and prosocial behavior: A meta-analytic review of the scientific literature. Psychol. Sci., 12: 353-359.

Anderson, C.A., 2004. An update on the effects of playing violent video games. J. Adolescence, 27: 113-122.

Deselms, J.L. and J.D. Altman, 2003. Immediate and prolonged effects of videogame violence. J. Applied Soc. Psychol., 33: 1553-1563.
Eseadi, C., 2016. Violent video games and violent media contents as correlates of aggressive behavior among in-school adolescents in Onitsha Education Zone of Anambra State, Nigeria. Master's Thesis, University of Nigeria Nsukka, Nigeria.

Eseadi, C., L.N. Onuigbo, P.N. Onwuasoanya and U.N. Eze, 2019. Violent video games play and aggressive behavior among adolescent students: Moderating effects of gender and parental mediation. Int. J. U. E. Serv. Sci. Technol., 12: 19-36.

Hartmann, T. and C. Klimmt, 2006. Gender and computer games: Exploring female's dislikes. J. Comput. Mediated Commun., 11: 910-931.

Hartmann, T., E. Toz and M. Brandon, 2010. Just a game? Unjustified virtual violence produces guilt in empathetic players. Media Psychol., 13: 339-363.

Hartmann, T., I. Moller and C. Krause, 2015. Factors underlying male and female use of violent video games. New Media Soc., 17: 1777-1794.

Kooijmans, T.A., 2004. Effects of video games on aggressive thoughts and behaviors during development. Rochester Institute of Technology, Rochester, New York, USA. http://www. personalityresearch.org/papers/kooijmans.html

Kutner, L.A., C.K. Olson, D.E. Warner and S.M. Hertzog, 2008. Parents and sons perspectives on video game play: A qualitative study. J. Adolesc. Res., 23: 76-96.

Lemmens, J.S., B.J. Bushman and E.A. Konijn, 2006. The appeal of violent video games to lower educated aggressive adolescent boys from two countries. Cyber Psychol. Behav., 9: 638-641.

Lucas, K. and J.L. Sherry, 2004. Sex differences in video game play: A communication-based explanation. Commun. Res., 31: 499-523.

Moller, I. and B. Krahe, 2009. Exposure to violent video games and aggression in German adolescents: A longitudinal analysis. Aggressive Behav. Off. J. Int. Soc. Res. Aggression, 35: 75-89.

Puri, K. and R. Pugliese, 2012. Sex, lies and video games: Moral panics or uses and gratifications. Bull. Sci. Technol. Soc., 32: 345-352.

Skinner, B.F., 1938. The Behaviour of Organisms: An Experimental Analysis. Appleton-Century-Crofts, New Jersey, USA., Pages: 467.

Wallenius, M. and R.L. Punamaki, 2008. Digital game violence and direct aggression in adolescence: A longitudinal study of the roles of sex, age and parent-child communication. J. Appl. Dev. Psychol., 29: 286-294. 